\title{
The role of dilution mediums in studies of fumigant insecticidal activity of essential oils
}

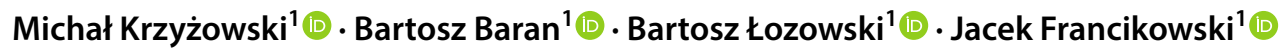

Received: 27 February 2020 / Revised: 8 May 2020 / Accepted: 25 May 2020 / Published online: 3 June 2020

(c) The Author(s) 2020

\begin{abstract}
The essential oils (EOs) are volatile plant extracts that are commonly considered as potential biopesticides. They present promising properties as relatively safe and potent insecticides, primarily delivered via fumigation. Such specificity of the EOs has led to the growing interest of researchers and, subsequently, to an increasing body of publications. The studies focusing on assessing the insecticidal action of EOs frequently require testing the effects of several dilutions of a given EO. To this end, researchers employ a range of solvents differing widely between the studies. While informative, the standardization concerning either tested oil or pest species is lacking in these studies. The presented study herein aimed to test whether the solvent used could affect the observed insecticidal activity of tested EO. As the model setup for studying the possible influence of solvents on the insecticidal effect of EOs, two EOs: mint and rosemary were chosen. The EOs were applied in fumigation assay against three economically important species of stored product pests: Callosobruchus maculatus, Sitophilus oryzae, and Tribolium castaneum. Each EO was tested in three concentrations-diluted with a range of solvents; dimethyl sulfoxide, acetone, methanol, ethanol, paraffin (mineral) oil, ultrapure water with $0.1 \%$ polysorbate 20 (TWEEN ${ }^{\circledR} 20$ ). The results confirm the hypothesis that the applied solvent could significantly alter the observed efficiency of tested EO. Such a result is of crucial value for conducting credible meta-analysis as well as for establishing a high standard of reproducibility.
\end{abstract}

Keywords Solvent $\cdot$ Dilution medium $\cdot$ Insecticide $\cdot$ Callosobruchus maculatus $\cdot$ Sitophilus oryzae $\cdot$ Tribolium confusum

\section{Key message}

- The essential oils insecticides research lacks standardization regarding solvent used for diluting the oils.

- The article investigated the potential impact of the commonly used solvent on the insecticidal effectiveness of two essential oils.

- The mortality assessment was conducted on three model species of the stored products pests, namely: Callosobruchus maculatus, Sitophilus oryzae and Tribolium confusum.

Communicated by C.G. Athanassiou.

Michał Krzyżowski

michal.krzyzowski.wbios@gmail.com

1 Laboratory of Insect Physiology and Ethology, Institute of Biology, Biotechnology and Environmental Protection, Faculty of Natural Sciences, University of Silesia in Katowice, Bankowa 9, 40-007 Katowice, Poland
- Tested solvents alone did not exhibit insecticidal action.

- The solvent in which essential oil is diluted could significantly affect its observed insecticidal properties.

\section{Introduction}

Pesticides are natural or synthetic chemicals extensively used in contemporary agriculture as a control agent of pests and diseases. According to a report by the US Environmental Protection Agency, more than two million tons of pesticides are currently used worldwide each year, and this value is constantly significantly increasing (Atwood and PaisleyJones 2017). After the herbicides, insecticides are the largest group among pesticides (29.5\%) (De et al. 2014). Due to their extensive use, these substances permeat the soil, water, and air, eventually entering and accumulating in trophic chains, thus, posing a considerable risk to non-target organisms, including vertebrates (Taylor et al. 2002). In order to 
counteract this problem, there is a growing emphasis on reducing the use of commonly applied pesticides in favor of biopesticides, other natural plant products, and physical methods of insect infestation control (Navarro and Navarro 2018). Among these methods, essential oils (EOs), which are mixtures of volatile secondary metabolites produced by plants, are becoming increasingly popular (Bakkali et al. 2008).

According to the scientometric analysis of publications from the Web of Science, conducted in a similar way as Isman and Grieneisen (2014), an increasing number of articles describe the potential use of EOs as insecticides (Fig. 1). That may be caused by, among other things, comparably low vertebrates toxicity, high availability, relatively low price, and reduced probability of generation of resistance in targeted insects (Koul et al. 2008; Arena et al. 2018). Many of these studies (44.05\%) focus on fumigation toxicity to determine the effect of EOs' vapors on the mortality of a specific insect species, and due to the relatively low $\mathrm{LC}_{50}$ and the sizes of the used experimental systems, most of the authors dilute essential oils in various substances (i.e., acetone, methanol, ethanol) (Mohamed and Abdelgaleil 2008; Dayaram and Khan 2016; Manju et al. 2018). However, to the author's best knowledge, no studies have yet been carried out to determine whether those substances affect the observed insecticidal properties of essential oils.

The aim of the current study was to investigate the potential impact of the most commonly used dilution mediums (DM) on the acute toxicity of two EOs on three model species of the stored products pests [namely: Callosobruchus maculatus (F.), Sitophilus oryzae (L.) and Tribolium confusum (Herbst)]. These specific species were selected due to having the highest number of publications reporting EOs' effect on them, and many reports describe research on the same insect species but use different DM. Therefore, we

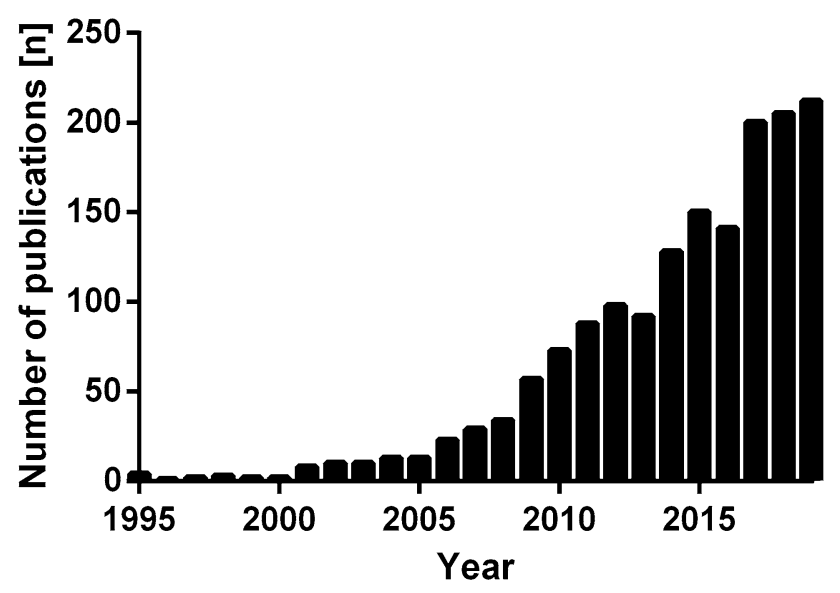

Fig. 1 Bibliometric analysis for query "Essential oil insecticide". http://apps.webofknowledge.com/ date of access: 20.02.2020 hypothesized that the DM used could significantly affect the observed insecticidal properties of tested EOs. Such discrepancy in methods could pose a crucial, but previously omitted, factor affecting the entire branch of studies on EOs.

\section{Materials and methods}

\section{Insects rearing}

Cowpea weevils, C. maculatus, were reared on mung beans (Vigna radiata) obtained from local vendors. 1-week-old, unsexed adults were used. Confused flour beetles, T. confusum, were reared in the plastic terrarium (ExoTerra "S" $16.5 \times 11 \times 13 \mathrm{~cm}$ ) on oat bran obtained from local vendors. Rice weevils, $S$. oryzae, were reared in a plastic terrarium (ExoTerra "S" $16.5 \times 11 \times 13 \mathrm{~cm}$ ) on barley groats obtained from local vendors. All the insects were reared in the constant conditions of $31 \pm 1{ }^{\circ} \mathrm{C}$, relative humidity $50 \pm 10 \%$, and the photoperiodic regime of $12 / 12 \mathrm{~h}$ light/dark.

\section{Used substances}

Analytical grade, undiluted methanol, ethanol (96\%), and acetone were obtained from P.P.H. STANLAB Poland. Dimethyl sulfoxide (DMSO) was purchased from POCH S.A. Poland, while paraffin oil was obtained from P.H.U. Agola Poland. For all water solutions, Tween 20 (SigmaAldrich) and ultrapure water (Millipore SimPak1 Purification system) were utilized. All of the EOs used in the assessments were water distilled and provided by Naturalne Aromaty sp. z o.o.

\section{Fumigation toxicity bioassays}

Mortality was assessed in five repetitions for each species (each repetition consisted of ten unsexed individuals; $n=1350$, sum of all individuals- $\Sigma_{n}=4050$ ). Each replication consisted of two EOs (selected based on previous pilot studies) diluted in six solvents, namely: dimethyl sulfoxide (DMSO), acetone, methanol, ethanol, paraffin (mineral) oil, and ultrapure water with $0.1 \%$ polysorbate 20 (TWEEN $^{\circledR}$ 20). Diluted in the following proportions $1.6 \mu \mathrm{l} ; 0.8 \mu \mathrm{l} ; 0.4$ $\mu \mathrm{l}$ of oils to $3.4 \mu \mathrm{l} ; 4.2 \mu \mathrm{l} ; 4.6 \mu \mathrm{l}$ of solvents, obtaining $5 \mu \mathrm{l}$ of test solutions (Fig. 2). For the positive control groups, pure EO's $(5 \mu \mathrm{l})$ were used and, respectively, for the negative control, pure solvents $(5 \mu \mathrm{l})$ and untreated insects were applied. $5 \mu \mathrm{l}$ of test solutions were applied on the cotton pad attached to the cover of the container and left for 5 min undisturbed to allow the evaporation. Insects were then put into the $50 \mathrm{ml}$ plastic containers with tight-fitting lids. Dead beetles were counted and removed after 24 and $48 \mathrm{~h}$. Insects were considered dead when no movement for $1 \mathrm{~h}$ was observed. All 


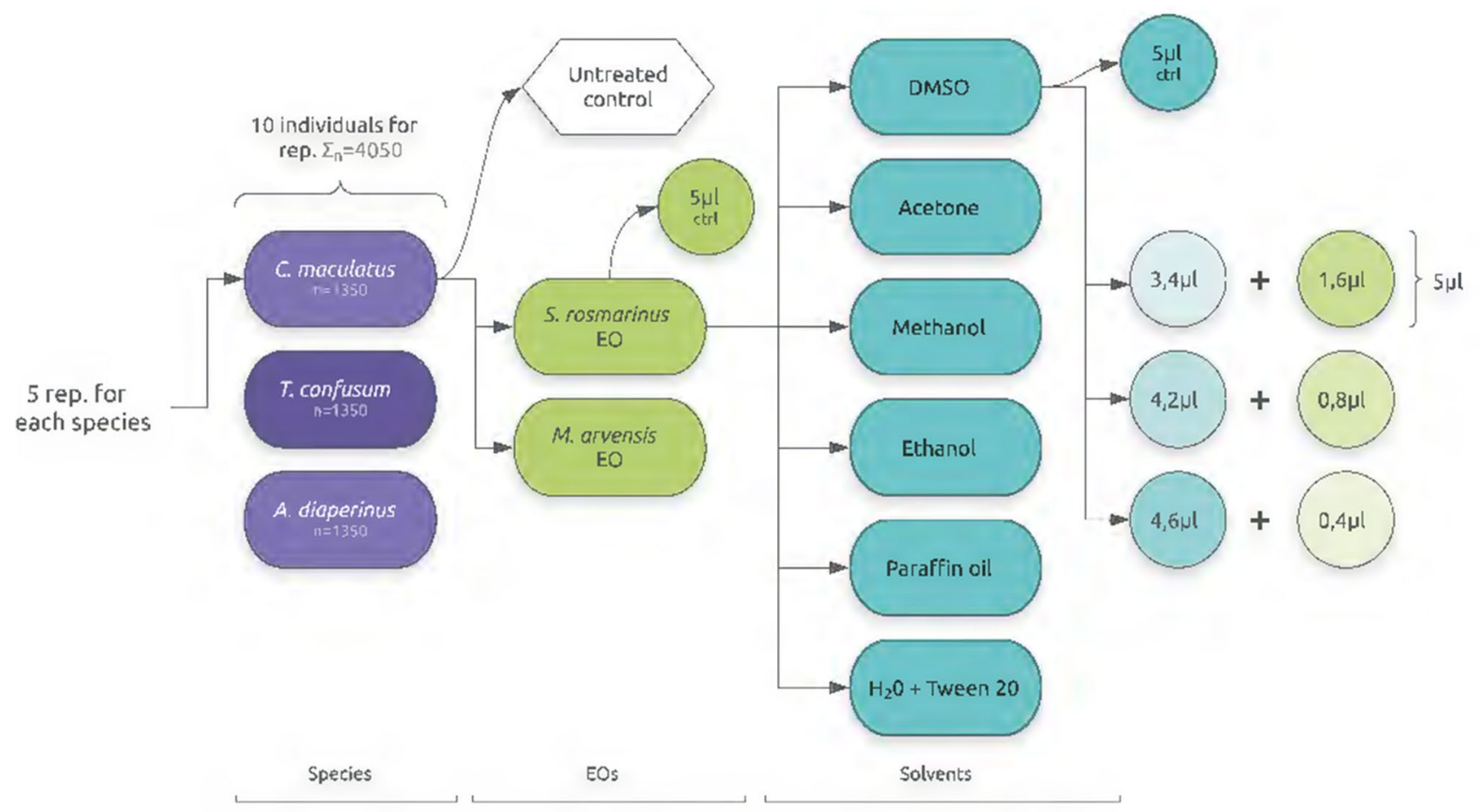

Fig. 2 Experimental procedure workflow. The single path on the flowchart represents one experimental variant

tests were carried out under the same conditions as during the rearing.

\section{Statistical analysis}

Statistical analysis was conducted using GraphPad Prism v6 software for Windows. Heatmaps were prepared using plot.ly (https://chart-studio.plot.ly/), experimental procedure flowchart was prepared with Lucidchart. Additionally, the multivariate analysis with the classical clustering method (paired method, Euclidean similarity index) was conducted using PAST v4 (Hammer et al. 2001). For all the obtained data, comparison tests between independent sampled groups on a single, non-normally distributed continuous variable were performed (Kruskal-Wallis with Dunn's multiple comparisons test, $p<0.05$ ). Due to a large number of used substances, many control tests had to be carried out (effect of solvents on insect mortality). Statistical analysis of the effects showed that there were no statistically significant differences between the control groups (Table 1). Therefore, the baseline control (without solvent) was used as a reference. To avoid confusion, the baseline control is abbreviated as "Ctrl" while the solvent controls groups are abbreviated, respectively, as "Ctrl $\mathrm{DMSO}$, , "Ctrl ${ }_{\text {Acetone }}$ ", "Ctrl $\mathrm{Oil}$ ", "Ctrl Ethanol $_{\text {, "Ctrl }}$ Tween0.1\%", "Ctrl Methanol .

\section{Results}

Baseline and all solvent control groups did not cause increased mortality and did not differ significantly from each other (Table 1), unlike the positive control groups (pure EOs), which differed significantly and caused relatively high mortality (Table 2).

The analysis of insect mortality after $24 \mathrm{~h}$ indicates differences between the species, used solvent, type, and volumes of EOs. In the case of $S$. oryzae, there were no differences in groups treated with rosemary EO, whereas in the case of $T$. confusum, there were no differences were observed in groups treated with mint EO. In T. confusum, differences were observed in the groups treated with $1.6 \mu$ of rosemary EO solution (ethanol, methanol and oil). In the case of $C$. maculatus, significant differences were found in the groups treated with solutions of $1.6 \mu \mathrm{l}$ of mint and rosemary EOs (acetone, methanol, ethanol, and oil) and $0.8 \mu \mathrm{l}$ of rosemary (ethanol) (Fig. 3).

After $48 \mathrm{~h}$ in the $S$. oryzae groups treated with rosemary EO solutions, no differences were observed. In the other groups, the effect similar to that after $24 \mathrm{~h}$ was observed except for increased mortality in S. oryzae (1.6 $\mu \mathrm{l}$ mint EO with oil solvent) and $T$. confusum $(0.8 \mu$ l rosemary EO) groups. A significant increase in mortality was observed in the T. confusum group treated with mint EO solutions in ethanol, methanol, and oil. Additionally, C. maculatus groups 
Table 1 Mean mortality of three beetle species (C. maculatus, $S$. oryzae and $T$. confusum) after 24 and $48 \mathrm{~h}$ in the negative control groups

\begin{tabular}{|c|c|c|c|c|c|c|}
\hline \multicolumn{7}{|c|}{ Mortality [\%] } \\
\hline & \multicolumn{2}{|c|}{ C. maculatus } & \multicolumn{2}{|c|}{ S. oryzae } & \multicolumn{2}{|c|}{ T. confusum } \\
\hline & $24 \mathrm{~h}$ & $48 \mathrm{~h}$ & $24 \mathrm{~h}$ & $48 \mathrm{~h}$ & $24 \mathrm{~h}$ & $48 \mathrm{~h}$ \\
\hline \multicolumn{7}{|c|}{ Negative control } \\
\hline Ctrl & $0 \mathrm{a}$ & $0 \mathrm{a}$ & $0 \mathrm{a}$ & $0 \mathrm{a}$ & $10 \mathrm{a}$ & $10 \mathrm{a}$ \\
\hline $\mathrm{Ctrl}_{\mathrm{DMSO}}$ & 0a & $0 \mathrm{a}$ & $0 \mathrm{a}$ & $10 \mathrm{a}$ & $0 \mathrm{a}$ & $0 \mathrm{a}$ \\
\hline $\mathrm{Ctrl}_{\text {Acetone }}$ & $0 \mathrm{a}$ & $0 \mathrm{a}$ & $0 \mathrm{a}$ & $0 \mathrm{a}$ & $0 \mathrm{a}$ & $0 \mathrm{a}$ \\
\hline $\mathrm{Ctrl}_{\mathrm{Oil}}$ & $0 \mathrm{a}$ & $0 \mathrm{a}$ & $0 \mathrm{a}$ & $0 \mathrm{a}$ & $0 \mathrm{a}$ & $0 \mathrm{a}$ \\
\hline $\mathrm{Ctrl}_{\text {Ethanol }}$ & $0 \mathrm{a}$ & $0 \mathrm{a}$ & $10 \mathrm{a}$ & $10 \mathrm{a}$ & $0 \mathrm{a}$ & $0 \mathrm{a}$ \\
\hline $\mathrm{Ctrl}_{\text {Tween }}$ & $10 \mathrm{a}$ & $10 \mathrm{a}$ & $0 \mathrm{a}$ & $0 \mathrm{a}$ & $0 \mathrm{a}$ & $0 \mathrm{a}$ \\
\hline $\mathrm{Ctrl}_{\text {Methanol }}$ & $0 \mathrm{a}$ & $0 \mathrm{a}$ & $10 \mathrm{a}$ & $10 \mathrm{a}$ & $0 \mathrm{a}$ & $0 \mathrm{a}$ \\
\hline
\end{tabular}

Means followed by the same letter do not significantly differ between the control groups from the same time point ( $p<0.05$, Kruskal-Wallis with Dunn's multiple comparisons test)

\begin{tabular}{|c|c|c|c|c|c|c|}
\hline \multicolumn{7}{|c|}{ Mortality [\%] } \\
\hline & \multicolumn{2}{|c|}{ C. maculatus } & \multicolumn{2}{|c|}{ S. oryzae } & \multicolumn{2}{|c|}{ T. confusum } \\
\hline & $24 \mathrm{~h}$ & $48 \mathrm{~h}$ & $24 \mathrm{~h}$ & $48 \mathrm{~h}$ & $24 \mathrm{~h}$ & $48 \mathrm{~h}$ \\
\hline \multicolumn{7}{|c|}{ Positive control } \\
\hline $\mathrm{Ctrl}_{\text {Mint }}$ & $70 \mathrm{a}$ & $70 \mathrm{a}$ & $60 \mathrm{a}$ & $60 \mathrm{a}$ & $40 \mathrm{a}$ & $50 \mathrm{a}$ \\
\hline $\mathrm{Ctrl}_{\text {Rosemary }}$ & $100 \mathrm{~b}$ & $100 \mathrm{~b}$ & $0 \mathrm{~b}$ & $\mathrm{Ob}$ & $100 \mathrm{~b}$ & $100 \mathrm{~b}$ \\
\hline
\end{tabular}

Means followed by the same letter do not significantly differ between the control groups from the same time point $(p<0.05$, Mann-Whitney test $)$
Table 2 Mean mortality of three beetle species (C. maculatus, S. oryzae and $T$. confusum) after 24 and $48 \mathrm{~h}$ in the positive control groups

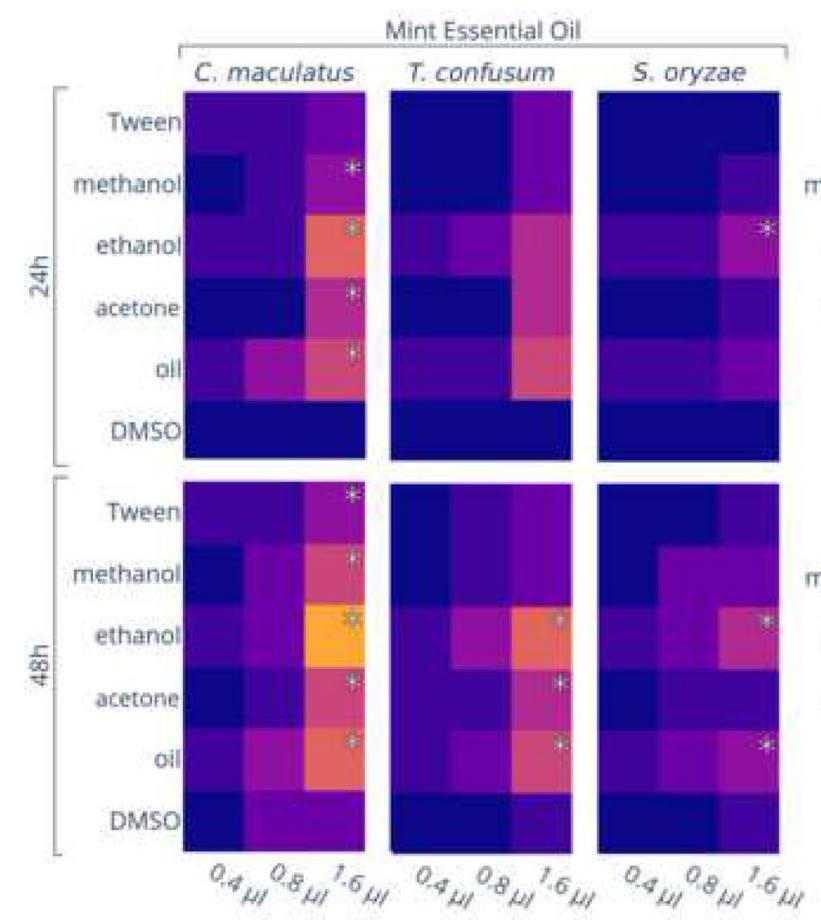

Fig. 3 Mortality of three beetle species (C. maculatus, S. oryzae, and T. confusum) after 24 and $48 \mathrm{~h}$. The matrix illustrates the mortality according to the volume of EOs and the solvents in which they were

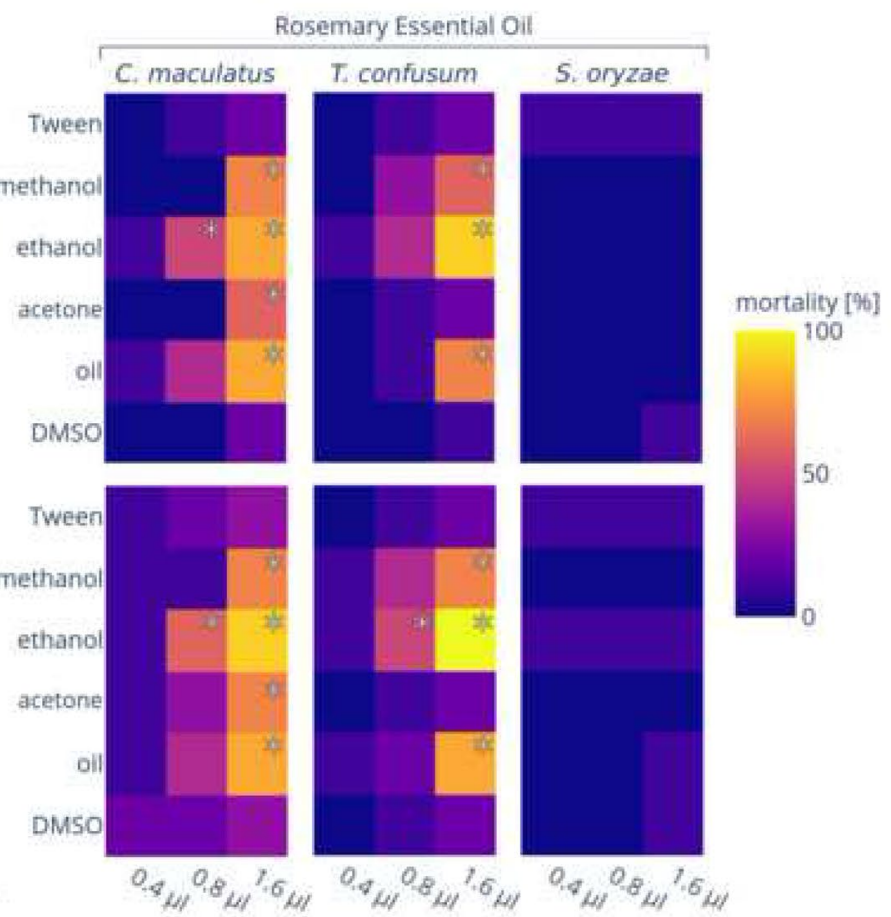

diluted (Kruskal-Wallis, Dunn's multiple comparisons test, $p<0.05$ ). The asterisk denotes significant differences between given groups and control groups 
treated with $1.6 \mu \mathrm{l}$ mint EO solution in Tween showed a significant increase in mortality.

To sum up, the increase in mortality after $48 \mathrm{~h}$ was mainly observed in $1.6 \mu \mathrm{l}$ of both EOs in the following solvents: acetone, ethanol, methanol, and oil. No significant effects were observed in insects treated with DMSO. Of all tested insect species, C. maculatus was the most sensitive to all the tested EOs, while, respectively, the $S$. oryzae was the least susceptible. Additionally, based on the obtained results, a more effective insecticidal action of rosemary EO, in comparison to the mint EO, can be observed.

Cluster analysis based on all insect mortality results (insect $\times \mathrm{EO} \times$ volume) showed solvent grouping into three main clusters. As separate clusters, the analysis indicated that oil and ethanol as one pair (cluster strongly separated from the other two), acetone and methanol as another, and as a third pair DMSO and Tween $1 \%$.

\section{Discussion}

EOs are an essential group of substances that can potentially replace commonly used pesticides. This results in a conspicuous trend of an increasing number of publications testing their effectiveness against insect pests. However, the research workflow usually depends on the methodology commonly applied in a particular research institution.
Considering the number of such institutions, the range of potential possibilities becomes very broad. This often results in significant differences in the methodology described in articles from the same field, and the obtained results are then compared with each other in discussions or meta-analyses. This may result in the accumulation of potential errors and misinterpretations of the results, as well as difficulties in the replicability of research. One such discrepancy may be the type of solvent used in EO's research. In this paper, we confirm the hypothesis that the choice of the solvent is of key importance for the effectiveness of EO's action on insects.

Out of over 40 analyzed papers describing assays in which the EOs were diluted with various solvents, acetone was used in over half. Nevertheless, for each species tested with the usage of acetone, studies involving other solvents were also conducted. This phenomenon is illustrated by the example of studies carried out on Callosobruchus chinensis and Tribolium castaneum beetles. Acetone was used as a solvent in fumigant toxicity assessment done on $C$. chinensis by Chaubey (2014) and on S. oryzae by Mohamed and Abdelgaleil (2008). Although Dayaram's and Khan's (2016) study was conducted on a phylogenetically similar species C. maculatus, ethanol was used for the same purpose, while Kim et al. (2003) used methanol in the study on S. oryzae. Such a pattern of methodological inconsistency is observed in many reports.

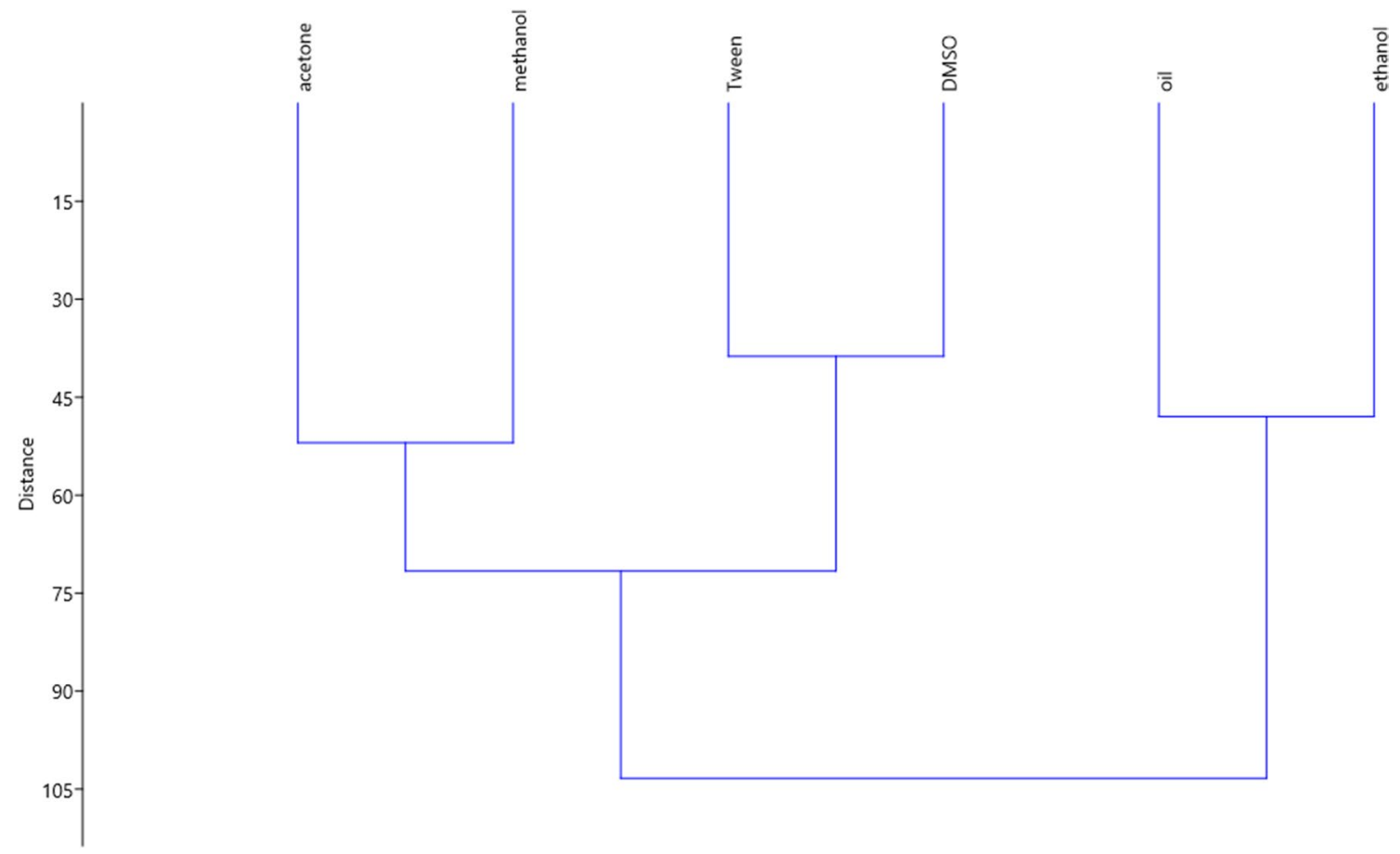

Fig. 4 Clustering of the solvents, based on the toxicity profiles of the used oils (Cohen correlation value 0.7655 ; Euclidean distance) 
The tested solvents alone did not significantly affect insects' mortality; thus, the observed differences in the effectiveness of tested EOs solutions were caused by EO-solvent interactions. This means that all or some constituents of the EO could be retained by the solvents to a varying degree, therefore being released unequally and affecting the treated insects differently. This could be caused by differing volatility of solvents and their polarity. Although discerning, which exact mechanism is responsible for the observed effects requires additional research. Thusly, we also claim that there is no universally applicable solvent, although a potential group of substances with promising properties seem to be volatile organic solvents [as was depicted by the efficiency dendrogram (Fig. 4)]. Therefore, the used substances should be carefully selected for the tested species.

\section{Author contributions}

MK and JF conceived and designed research. MK conducted experiments. JK and $\mathrm{B} €$ analyzed data. MK and BB wrote the manuscript. All authors read and approved the manuscript.

Funding This research did not receive any specific grant from funding agencies in the public, commercial, or not-for-profit sectors.

\section{Compliance with ethical standards}

Conflict of interest The authors declare no conflicts of interest.

Ethical approval This article does not contain any studies with human participants or animals (vertebrates) performed by any of the authors.

Open Access This article is licensed under a Creative Commons Attribution 4.0 International License, which permits use, sharing, adaptation, distribution and reproduction in any medium or format, as long as you give appropriate credit to the original author(s) and the source, provide a link to the Creative Commons licence, and indicate if changes were made. The images or other third party material in this article are included in the article's Creative Commons licence, unless indicated otherwise in a credit line to the material. If material is not included in the article's Creative Commons licence and your intended use is not permitted by statutory regulation or exceeds the permitted use, you will need to obtain permission directly from the copyright holder. To view a copy of this licence, visit http://creativecommons.org/licenses/by/4.0/.

\section{References}

Arena JS, Omarini AB, Zunino MP, Peschiutta ML, Defagó MT, Zygadlo JA (2018) Essential oils from Dysphania ambrosioides and Tagetes minuta enhance the toxicity of a conventional insecticide against Alphitobius diaperinus. Ind Crops Prod 122:190-194. https://doi.org/10.1016/j.indcrop.2018.05.077

Atwood D, Paisley-Jones C (2017) Pesticides industry sales and usage: 2008-2012 market estimates. US Environmental Protection Agency, Washington, DC, p 20460

Bakkali F, Averbeck S, Averbeck D, Idaomar M (2008) Biological effects of essential oils-a review. Food Chem Toxicol 46:446-475. https://doi.org/10.1016/j.fct.2007.09.106

Chaubey MK (2014) Biological activities of Allium sativum essential oil against pulse beetle, Callosobruchus chinensis (Coleoptera: Bruchidae). Herba Pol 60:41-55. https://doi.org/10.2478/ hepo-2014-0009

Dayaram L, Khan A (2016) Repellent, fumigant and contact toxicity of Salvia officinalis, Rosmarinus officinalis and Coriandrum sativum against Callosobruchus maculatus (Fab.) (Coleoptera: Bruchidae). Int J Trop Agric 34:893-902

De A, Bose R, Kumar A, Mozumdar S (2014) Targeted delivery of pesticides using biodegradable polymeric nanoparticles. Springer, New Delhi, pp 5-6. https://doi.org/10.1007/978-81-322-1689-6_2

Hammer $\varnothing$, Harper DAT, Ryan PD (2001) PAST: paleontological statistics software package for education and data analysis. Palaeontol Electron 4:9

Isman M, Grieneisen M (2014) Botanical insecticide research: many publications, limited useful data. Trends Plant Sci 19:140-145. https://doi.org/10.1016/j.tplants.2013.11.005

Kim SI, Roh JY, Kim DH, Lee HS, Ahn YJ (2003) Insecticidal activities of aromatic plant extracts and essential oils against Sitophilus oryzae and Callosobruchus chinensis. J Stored Prod Res 39:293303. https://doi.org/10.1016/S0022-474X(02)00017-6

Koul O, Walia S, Dhaliwal GS (2008) Essential oils as green pesticides: potential and constraints. Biopestic Int 4:63-84

Manju K, Jayaraj J, Shanti M (2018) Preparation of dust formulation of essential and aromatic oils and testing the bioefficacy against pulse beetle Callosobruchus maculatus (Fab.) (Coleoptera: Bruchidae) in green gram storage. J Entomol Zool Stud 6:185-189

Mohamed MI, Abdelgaleil SA (2008) Chemical composition and insecticidal potential of essential oils from Egyptian plants against Sitophilus oryzae (L.) (Coleoptera: Curculionidae) and Tribolium castaneum (Herbst) (Coleoptera: Tenebrionidae). Appl Entomol Zool 43:599-607. https://doi.org/10.1303/aez.2008.599

Navarro S, Navarro H (2018) Recent advances in stored product protection. Springer, Berlin, pp 99-141

Taylor MD, Klaine SJ, Carvalho FP, Barcelo D (2002) Pesticide residues in coastal tropical ecosystems: distribution, fate and effects. CRC Press, Boca Raton

Publisher's Note Springer Nature remains neutral with regard to jurisdictional claims in published maps and institutional affiliations. 